\title{
Unsteady MHD Mixed Convection Flow, Heat and Mass Transfer over an Exponentially Stretching Sheet with Suction, Thermal Radiation and Hall Effect
}

\author{
S. Mahaboobjan, K. Sreelakshmi and G. Sarojamma \\ (Department of Applied Mathematics, Sri Padmavati Mahila Visvavidyalayam, Tirupati-517502, India)
}

\begin{abstract}
In this paper the characteristics of flow, radiative heat and mass transfer of a viscous fluid flow over a permeable sheet stretching exponentially with Hall currents in the presence of heat generation and first order chemical reaction are investigated. The non - linear partial differential equations governing the flow are transformed into a set of self similar equations which are then solved numerically. The computational results are graphically presented and discussed. The analysis shows that the Lorentz force resists the primary velocity and the Hall parameter has an opposite effect on it while secondary velocity experiences a reversal effect. The radiation parameter and magnetic field produce thicker thermal boundary layers.
\end{abstract}

Keywords: Exponentially Stretching Sheet, Hall Currents, MHD, Unsteady.

\section{Introduction}

Magyari and Keller [1] are the first researchers to investigate the free convection flow, heat and mass transfer of an incompressible fluid from an exponentially stretching vertical surface. They obtained similarity solutions pertaining to an exponential stretching and exponential temperature of the continuous surface. Following the study of Magyari and Keller [1], Elbashbeshy [2] discussed the heat transfer over an exponentially stretching surface with suction. Partha et al. [3] investigated the flow past an exponentially stretching surface of a viscous fluid taking into account of viscous heating. This study was extended by Sajid and Hayat [4] by considering the thermal radiation and an analytical solution was obtained using homotopy analysis method. Later Bidin and Nazar [5] made a numerical study of this problem. Sanjayanand and Khan [6] explored the heat and mass transfer characteristics of a viscoelastic fluid flow due to a stretching surface with viscous dissipation and elastic deformation. Ishak [7] analysed the MHD boundary layer flow and heat transfer of a viscous fluid over an exponentially stretching sheet taking the effect of thermal radiation. Nadeem et al. [8] examined the effect of thermal radiation on the boundary layer flow of a Jeffery fluid induced by a surface stretching exponentially. Battacharyya [9] studied the boundary layer flow and heat transfer over an exponentially sheet. Swati Mukhopadyay et al. [10] studied the features of flow and heat transfer of a viscous incompressible fluid past a permeable exponential stretching sheet with thermal radiation effect. Elbashbeshy et al. [11] made a numerical investigation of flow and heat transfer characterstics of an incompressible fluid over an exponentially stretching surface with thermal radiation. Mukhopadyay et al. [12] investigated the influence of a chemically reactive solute and velocity slip on the boundary layer flow and mass transfer towards an exponentially permeable stretching plate. Nadeem and Hussain [13] investigated the heat transfer of a pseudo plastic fluid past an exponentially porous stretching surface modeling as a Williamson fluid. The steady MHD mixed convective flow past an exponentially stretching sheet was examined by Aziz and Nabil [14] taking thermal radiation and Hall currents.

In this paper we made an attempt to analyse influence of thermal radiation, temperature dependent heat source on the unsteady boundary layer flow heat and mass transfer of a viscous fluid over an exponentially stretching sheet with Hall currents and first order chemical reaction.

\section{Mathematical formulation}

Consider an unsteady three-dimensional mixed convection boundary layer flow of an incompressible viscous fluid along a stretching surface. The $\mathrm{x}$-axis is taken along the stretching surface in the direction of motion and the $y$-axis is perpendicular to it. The stretching surface has the velocity $U_{w}(x, t)=U_{0}(1-$ $\alpha \mathrm{t})^{-1} \mathrm{e}^{\mathrm{x} / \mathrm{L}}$, the temperature distribution $\mathrm{T}_{\mathrm{w}}(\mathrm{x}, \mathrm{t})=\mathrm{T}_{\infty}+\mathrm{T}_{0}(1-\alpha \mathrm{t})^{-2} \mathrm{e}^{\mathrm{x} / 2 \mathrm{~L}}$ and the concentration distribution $\mathrm{C}_{\mathrm{w}}(\mathrm{x}, \mathrm{t})=\mathrm{C}_{\infty}+\mathrm{C}_{0}(1-\alpha \mathrm{t})^{-2} \mathrm{e}^{\mathrm{x} / 2 \mathrm{~L}}$ where $\mathrm{U}_{0}$ is the reference velocity, $\alpha$ is a positive constant with dimension reciprocal time, $\mathrm{L}$ is the reference length, $\mathrm{t}$ is the time, $\mathrm{T}_{\infty}$ is the fluid temperature far away from the stretching surface, $\mathrm{T}_{0}$ is the fluid temperature adjacent to the stretching surface, $\mathrm{C}_{\infty}$ is the fluid concentration far away from the stretching surface and $\mathrm{C}_{0}$ is the fluid concentration adjacent to the stretching surface. A uniform magnetic field of strength $B_{0}$ is applied normally to the stretching surface which produces magnetic effect in the $\mathrm{x}$-axis. The effect of the induced magnetic field is neglected by taking a small magnetic Reynolds number. The 
continuity, momentum, energy and concentration equations governing such type of flow invoking the Boussinesq's approximation can be written as

$$
\begin{aligned}
& \frac{\partial u}{\partial x}+\frac{\partial v}{\partial y}=0 \\
& \frac{\partial u}{\partial t}+u \frac{\partial u}{\partial x}+v \frac{\partial u}{\partial y}=v \frac{\partial^{2} u}{\partial y^{2}}+g \beta\left(T-T_{\infty}\right)+g \beta^{*}\left(C-C_{\infty}\right)-\frac{\sigma B_{0}^{2}}{\rho\left(1+m^{2}\right)}(u+m w) \\
& \frac{\partial w}{\partial t}+u \frac{\partial w}{\partial x}+v \frac{\partial w}{\partial y}=v \frac{\partial^{2} w}{\partial y^{2}}+\frac{\sigma B_{0}^{2}}{\rho\left(1+m^{2}\right)}(m u-w) \\
& \frac{\partial T}{\partial t}+u \frac{\partial T}{\partial x}+v \frac{\partial T}{\partial y}=\frac{K}{\rho c_{p}} \frac{\partial^{2} T}{\partial y^{2}}-\frac{1}{\rho c_{p}} \frac{\partial q_{r}}{\partial y}+\frac{Q_{0}}{\rho c_{p}}\left(T-T_{\infty}\right) \\
& \frac{\partial C}{\partial t}+u \frac{\partial C}{\partial x}+v \frac{\partial C}{\partial y}=D \frac{\partial^{2} C}{\partial y^{2}}-k\left(C-C_{\infty}\right)
\end{aligned}
$$

The radiative heat flux by using Rosseland approximation can be written as

$\mathrm{q}_{\mathrm{r}}=-\frac{4 \sigma_{s}}{3 k^{*}} \frac{\partial T^{4}}{\partial y}$

where $\sigma_{\mathrm{s}}$ is the Stefen-Boltzman constant and $\mathrm{k}^{*}$ is the absorption coefficient.

$T^{4}$ may be linearly expanded in a Taylor's series about $T_{\infty}$ to get

$\mathrm{T}^{4}=\mathrm{T}_{\infty}^{4}+4 \mathrm{~T}_{\infty}^{3}\left(\mathrm{~T}-\mathrm{T}_{\infty}\right)+6 \mathrm{~T}_{\infty}^{2}\left(\mathrm{~T}-\mathrm{T}_{\infty}\right)^{2}+\cdots$,

and neglecting higher order terns beyond the first degree in $\left(T-T_{\infty}\right)$,

we obtain $\mathrm{T}^{4} \cong 4 \mathrm{~T}_{\infty}^{3} \mathrm{~T}-3 \mathrm{~T}_{\infty}^{4}$

$\mathrm{q}_{\mathrm{r}}=-\frac{16 \sigma_{\mathrm{s}} \mathrm{T}_{\infty}^{3}}{3 \mathrm{k}^{*}} \frac{\partial^{2} \mathrm{~T}}{\partial \mathrm{y}^{2}}$

Substituting equation (7) into equation (4) to get

$$
\frac{\partial \mathrm{T}}{\partial \mathrm{t}}+\mathrm{u} \frac{\partial \mathrm{T}}{\partial \mathrm{x}}+\mathrm{v} \frac{\partial \mathrm{T}}{\partial \mathrm{y}}=\frac{1}{\rho c_{\mathrm{p}}}\left[\left(\mathrm{K}+\frac{16 \sigma_{\mathrm{s}} \mathrm{T}_{\infty}^{3}}{3 \mathrm{k}^{*}}\right) \frac{\partial^{2} \mathrm{~T}}{\partial \mathrm{y}^{2}}+\mathrm{Q}_{0}\left(\mathrm{~T}-\mathrm{T}_{\infty}\right)\right]
$$

The boundary conditions are

$$
\begin{aligned}
& u=U_{w}(x, t), v=-V_{w}(x, t), w=0, T=T_{w}(x, t), C=C_{w}(x, t) \text { at } y=0, \\
& u \rightarrow 0, w \rightarrow 0, T \rightarrow T_{\infty}, C \rightarrow C_{\infty} \text { as } y \rightarrow \infty
\end{aligned}
$$

where $\mathrm{u}, \mathrm{v}$ and $\mathrm{w}$ are the fluid velocity components along $\mathrm{x}, \mathrm{y}$ and $\mathrm{z}$ axes, respectively, $v$ is the kinematic viscosity, $\mathrm{g}$ is the gravity field, $\beta$ is the volumetric coefficient of thermal expansion, $\beta^{*}$ is the coefficient of expansion with concentration, $\rho$ is the density of the fluid, $\mathrm{T}$ is the fluid temperature, $\mathrm{C}$ is the fluid concentration, $\sigma$ is the electrical conductivity, $c_{p}$ is the specific heat at constant pressure, $\mathrm{K}$ is the thermal conductivity of the medium, $q_{r}$ is the radiation heat flux, $Q_{0}$ is the uniform volumetric heat generation and absorption, $\mathrm{D}$ is the mass diffusivity, $\mathrm{k}$ is the chemical reaction, $\mathrm{V}_{\mathrm{w}}(\mathrm{x}, \mathrm{t})=\mathrm{f}_{\mathrm{w}}\left(\mathrm{U}_{0} \mathrm{v} / 2 \mathrm{~L}(1-\alpha \mathrm{t})\right)^{1 / 2} \mathrm{e}^{\mathrm{x} / 2 \mathrm{~L}}$ is the velocity of suction $\left(V_{w}>0\right), f_{w} \geq 0$ is the suction parameter.

We introduce the stream function $\psi(x, y)$ such that $u=\frac{\partial \psi}{\partial y}$ and $v=-\frac{\partial \psi}{\partial x}$.

\section{Method of Solution}

The governing partial differential equations (2), (3), (5) and (8) can be reduced to a set of ordinary differential equations on introducing the following similarity variables:

$$
\begin{aligned}
& \eta=\sqrt{\frac{\mathrm{U}_{0}}{2 v \mathrm{~L}(1-\alpha \mathrm{t})}} \mathrm{e}^{\mathrm{x} / 2 \mathrm{~L}} \mathrm{y}, \\
& w=\frac{\mathrm{U}_{0}}{(1-\alpha \mathrm{t})} \mathrm{e}^{\mathrm{x} / \mathrm{L}} h(\eta), \\
& \psi(\mathrm{x}, \mathrm{y})=\sqrt{\frac{2 \mathrm{U}_{0} v \mathrm{~L}}{(1-\alpha \mathrm{t})}} \mathrm{e}^{\mathrm{x} / 2 \mathrm{~L}} \mathrm{f}(\eta), \\
& \mathrm{T}=\mathrm{T}_{\infty}+\frac{\mathrm{T}_{0}}{(1-\alpha \mathrm{t})^{2}} \mathrm{e}^{\mathrm{x} / 2 \mathrm{~L}} \theta(\eta), \\
& \mathrm{C}=\mathrm{C}_{\infty}+\frac{\mathrm{C}_{0}}{(1-\alpha \mathrm{t})^{2}} \mathrm{e}^{\mathrm{x} / 2 \mathrm{~L}} \phi(\eta),
\end{aligned}
$$
equations:

Using (10) to (14) in equations (2), (3), (5) and (8) we obtain the following set of ordinary differential

$$
\begin{aligned}
& \mathrm{f}^{\prime \prime \prime}+\mathrm{ff}^{\prime \prime}-2 \mathrm{f}^{\prime 2}-\mathrm{Le}^{-\mathrm{X}}\left(\mathrm{A}\left(2 \mathrm{f}^{\prime}+\eta \mathrm{f}^{\prime \prime}\right)+\frac{2 \mathrm{M}}{1+\mathrm{m}^{2}}\left(\mathrm{f}^{\prime}+\mathrm{mh}\right)-2 \mathrm{e}^{-\mathrm{X} / 2}\left(\mathrm{G}_{\mathrm{r}} \theta+\mathrm{G}_{\mathrm{c}} \phi\right)\right)=0 \\
& \mathrm{~h}^{\prime \prime}+\mathrm{fh}^{\prime}-2 \mathrm{f}^{\prime} \mathrm{h}-\mathrm{Le}^{-\mathrm{X}}\left(\mathrm{A}\left(2 \mathrm{~h}+\eta \mathrm{h}^{\prime}\right)-\frac{2 \mathrm{M}}{1+\mathrm{m}^{2}}\left(\mathrm{mf}^{\prime}-\mathrm{h}\right)\right)=0 \\
& (1+\mathrm{Nr}) \theta^{\prime \prime}+\operatorname{Pr}\left(\mathrm{f} \theta^{\prime}-\mathrm{f}^{\prime} \theta-\mathrm{Le}^{-\mathrm{X}} \mathrm{A}\left(4 \theta+\eta \theta^{\prime}\right)+\delta \theta\right)=0 \\
& \phi^{\prime \prime}+\mathrm{Sc}\left(\mathrm{f} \phi^{\prime}-\mathrm{f}^{\prime} \phi-\mathrm{Le}^{-\mathrm{X}} \mathrm{A}\left(4 \phi+\eta \theta^{\prime}\right)-\gamma \phi\right)=0
\end{aligned}
$$

Where the primes denote the differentiation with respect to $\eta, X=x / L$ is the dimensionless coordinate, $A=\alpha / U_{0}$ is the unsteadiness parameter, $\mathrm{M}=\sigma \mathrm{B}_{0}^{2}(1-\alpha \mathrm{t}) / \mathrm{U}_{0} \rho$ is the Magnetic parameter, $\mathrm{G}_{\mathrm{r}}=\mathrm{g} \beta \mathrm{T}_{0} / \mathrm{U}_{0}^{2}$ is the thermal Grashof number, $\mathrm{G}_{\mathrm{c}}=\mathrm{g} \beta^{*} \mathrm{C}_{0} / \mathrm{U}_{0}^{2}$ is the solutal Grashof number, $\operatorname{Pr}=\rho c_{\mathrm{p}} v / \mathrm{K}$ is 
the Prandtl number, $\mathrm{Nr}=16 \sigma_{\mathrm{s}} \mathrm{T}_{\infty}^{3} / 3 \mathrm{Kk}^{*}$ is the thermal radiation parameter, $\delta=2 \mathrm{Q}_{0} \mathrm{~L} / \mathrm{U}_{\mathrm{w}} \rho \mathrm{c}_{\mathrm{p}}$ is the heat generation $(\delta>0)$ and absorption $(\delta<0)$ parameter, Sc $=v / D$ is the Schmidt number and $\gamma=2 \mathrm{~kL} / \mathrm{U}_{\mathrm{w}}$ is the chemical reaction parameter.

The corresponding boundary conditions are

$$
\begin{aligned}
& \eta=0: f=f_{w}, f^{\prime}=1, h=0, \theta=1, \phi=1, \\
& \eta \rightarrow \infty: f^{\prime} \rightarrow 0, h \rightarrow 0, \theta \rightarrow 0, \phi \rightarrow 0,
\end{aligned}
$$

The physical quantities of engineering interest in this problem are the skin friction coefficient $\mathrm{C}_{\mathrm{f}}$ and the local Nusselt number $\mathrm{Nu}_{\mathrm{x}}$ and local Sherwood number $\mathrm{Sh}_{\mathrm{x}}$ which are defined as

$$
\begin{array}{ll}
\mathrm{C}_{\mathrm{fx}}=\frac{2 \mu(\partial \mathrm{u} / \partial \mathrm{y})_{\mathrm{y}=0}}{\sqrt{\mathrm{Re}_{\mathrm{x}}},}, & \mathrm{C}_{\mathrm{fz}}=\frac{2 \mu(\partial \mathrm{w} / \partial \mathrm{y})_{\mathrm{y}=0}}{\sqrt{\mathrm{Re}_{\mathrm{x}}}}, \\
\mathrm{Nu}_{\mathrm{x}}=-\frac{\mathrm{x}(\partial \mathrm{T} / \partial \mathrm{y})_{\mathrm{y}=0}}{\mathrm{~T}_{\mathrm{w}}-\mathrm{T}_{\infty}}, & \mathrm{Sh}_{\mathrm{x}}=-\frac{\mathrm{x}(\partial \mathrm{C} / \partial \mathrm{y})_{\mathrm{y}=0}}{\mathrm{C}_{\mathrm{w}}-\mathrm{C}_{\infty}}, \\
\frac{1}{2} \mathrm{C}_{\mathrm{fx}} \sqrt{\mathrm{Re}_{\mathrm{x}}}=\mathrm{f}^{\prime \prime}(0), & \frac{1}{2} \mathrm{C}_{\mathrm{fz}} \sqrt{\mathrm{Re}_{\mathrm{x}}}=\mathrm{h}^{\prime}(0), \\
\mathrm{Nu}_{\mathrm{x}} / \sqrt{\mathrm{Re}_{\mathrm{x}}}=-\theta^{\prime}(0), & \mathrm{Sh}_{\mathrm{x}} / \sqrt{\operatorname{Re}_{\mathrm{x}}}=-\phi^{\prime}(0),
\end{array}
$$

where $\mu=\mathrm{k} / \rho \mathrm{c}_{\mathrm{p}}$ is the dynamic viscosity of the fluid and $\mathrm{Re}_{\mathrm{x}}=\mathrm{x} \mathrm{U}_{\mathrm{w}} / v$ is Reynolds number.

\section{Results and Discussion}

The present analysis aims at analysing how the flow characteristics are influenced by Hall currents, chemical reaction, temperature dependent heat source and thermal radiation. Runge - Kutta -Fehlberg method is employed to obtain the numerical solution of equations (15)-(20). To validate numerical solution, the temperature gradient on the surface of the present study is compared with that evaluated by Elbashbeshy et al. [11] neglecting Hall currents and mass diffusion in the unsteady case and Ishak [7] in the steady case and with

\begin{tabular}{|c|c|c|c|c|c|c|c|}
\hline $\mathbf{N r}$ & $\mathbf{M}$ & Pr & $\begin{array}{c}\text { Elbashbehy } \\
{[15]}\end{array}$ & Bidin and Nazar [5] & $\begin{array}{c}\text { Ishak } \\
{[7]}\end{array}$ & Elbashbehy et al. [11] & $\begin{array}{c}\text { Present } \\
\text { results }\end{array}$ \\
\hline \multirow[t]{5}{*}{0.0} & 0.0 & 0.72 & 0.76778 & \multirow[b]{2}{*}{0.9548} & & 0.76728 & 0.76728 \\
\hline & & $\begin{array}{l}1.0 \\
2.0\end{array}$ & 0.95478 & & $\begin{array}{l}0.9548 \\
1.4715\end{array}$ & $\begin{array}{l}0.95478 \\
1.47146\end{array}$ & $\begin{array}{l}0.95478 \\
1.47146\end{array}$ \\
\hline & & 3.0 & 1.86907 & \multirow[t]{3}{*}{1.8691} & 1.8691 & 1.86907 & 1.86907 \\
\hline & & 5.0 & & & 2.5001 & 2.50013 & 2.50013 \\
\hline & & 10.0 & 3.66037 & & 3.6604 & 3.66037 & 3.66036 \\
\hline 0.0 & 0.5 & 1.0 & & & 0.8611 & 0.86109 & 0.86109 \\
\hline $2 / 3$ & & 1.0 & & 0.6765 & & 0.67650 & 0.67650 \\
\hline & & 3.0 & & 1.3807 & & 1.38075 & 1.38075 \\
\hline
\end{tabular}
Elbashbeshy [15], Bidin and Nazar [5] ignoring Lorentz force, thermal and solutal buoyancy, heat generation/absorption and suction. $\mathrm{X}=\mathrm{A}=\mathrm{Gr}=\mathrm{Gc}=\delta=\mathrm{M}=\mathrm{f}_{\mathrm{w}}=\phi=0$ for different values of $\mathrm{Pr}$ and $\mathrm{Nr}$. The compared values of $-\theta^{\prime}(0)$ are presented in Table 1 which are found to be in good agreement with the said published results.

Table 1 Comparison values of $-\theta^{\prime}(0)$ for $X=A=\lambda=\delta=f_{w}=\phi=0$

In order to analyze the effects of Hall current, thermal buoyancy force, solutal buoyancy force, chemical reaction, heat source/absorption, thermal radiation and time on the flow-field, the computational values of the primary and secondary velocities of the fluid in the boundary layer region, temperature distribution and mass concentration are presented graphically for various values of magnetic parameter $\mathrm{M}$, Hall current parameter $\mathrm{m}$, suction parameter $\mathrm{f}_{\mathrm{w}}$, thermal Grashof number Gr, solutal Grashof number Gc, Prandtl number Pr, unsteady parameter A, thermal radiation parameter $\mathrm{Nr}$, chemical reaction parameter $\gamma$ and Schmidt number Sc.

Fig. 1 and Fig. 2 reveal that the primary velocity decreases throughout the boundary layer region with increasing values of magnetic parameter. The deceleration in the velocity is owing to the retarding action of the Lorentz force. Secondary velocity increases rapidly near the plate attaining maximum value and then decreases in the rest of the region eventually approaching the free stream value. The secondary velocity significantly increases with the magnetic field unlike the primary velocity. Fig. 3 and Fig. 4 show the influence of Hall current on the primary velocity and secondary velocity. It is observed that on increasing Hall parameter (m) the primary velocity increases nominally in the vicinity of the plate while the secondary velocity increases significantly throughout boundary layer region. This shows that Hall current tends to accelerate the fluid throughout the boundary layer region which is in conformity of the fact that the secondary velocity arises due to Hall currents. Figs. $5-8$ illustrate the variation of velocities, temperature and concentration with unsteady parameter. It is revealed that the thickness of the hydrodynamic boundary layer, thermal boundary layer and the solutal boundary layer decreases with increase in the unsteady parameter. Figs. $9-12$ depict the effect of thermal and solutal buoyancy forces on the primary and secondary velocities. It is observed that both the 
velocities increase on increasing Gr and Gc. As Gr (Gc) amounts to the relative strength of thermal (solutal) buoyancy force to viscous force, both thermal and concentration buoyancy forces tend to accelerate both the velocities throughout the boundary layer region. The influence of suction/injection $f_{w}$ on the velocity distributions are plotted in Fig. 13 and Fig.14. It is observed that primary velocity decreases with increasing suction parameter and the injection (blowing) accelerates the flow. The wall suction $\left(\mathrm{f}_{w}>0\right)$ results in thinner boundary layers with a fall in the velocity. For blowing $\left(f_{w}<0\right)$ an opposite trend is noticed. The behavior of the secondary velocity with $f_{w}$ is similar to that of the primary velocity. However, in this case the influence of $f_{w}$ is stronger than that on primary velocity. $f_{w}=0$ correspond to the impermeable stretching surface.

Fig. 15 indicates that increasing values of Prandtl number decrease the temperature. The reduction in the thickness of the thermal boundary layer is justified in view of the fact that increasing values of Pr correspond to reduction in the thermal conductivity resulting in decrease in temperature. The influence of thermal radiation on temperature is depicted in Fig. 16. It is observed that the temperature is enhanced for increasing values of $\mathrm{Nr}$ and thus resulting in the increasing of the thickness of both thermal and hydrodynamic boundary layers. The thermal radiation facilitates additional means to diffuse energy as an enhancement in the radiation parameter which corresponds to a reduction in the Rosseland mean absorption coefficient $\mathrm{K}^{*}$ for fixed values of $T_{\infty}$ and $\mathrm{k}$. Fig. 17 reveals that the temperature is enhanced in the presence of heat source. The heat source releases energy in the thermal boundary layer resulting in the rise of temperature. On increasing $\delta>0$ the temperature further rises. In the case of heat absorption $\delta<0$ (heat sink) the temperature falls with decreasing values of $\delta<0$ owing to the absorption of energy in the thermal boundary layer. From Fig. 18 the species concentration is observed to reduce with increasing values of the Schmidt number throughout the region which is associated with thinner solutal boundary layers. Physically, increasing values of Sc imply decrease of molecular diffusion D. Thus the mass diffusion leads to an enhancement in the species concentration. The influence of chemical reaction rate parameter $\gamma$ on the species concentration for generative chemical reaction is depicted in Fig. 19. It is found that species concentration with its highest value at the plate decreases slowly till it reaches the minimum value i.e., zero at the far downstream. Further, increasing of the chemical reaction decreases concentration of species in the boundary layer due to the fact that destructive chemical reduces the thickness of the solutal boundary layer and increases the mass transfer. The skin friction coefficient, local Nusselt number and local Sherwood number for different values of the governing parameters are presented in Table 2. The skin friction coefficient in the $\mathrm{x}$-direction reduces for increasing values of the unsteady parameter while it increases in the z-direction. The rate of heat transfer is observed to increase with increasing unsteady parameter while the mass transfer is more for small times. The increase in the magnetic parameter lowers the skin friction coefficient corresponding to the primary velocity and while skin friction coefficient corresponding to the secondary velocity, temperature and the Sherwood number show an increasing tendency. The influence of the Hall parameter is to increase the skin friction coefficient in both $\mathrm{x}$ and $\mathrm{z}$ - directions, Nusselt number and Sherwood number. The thermal buoyancy and solutal buoyancy parameters both enhance the skin friction coefficient in the $\mathrm{x}$ and $\mathrm{z}$ - directions, the Nusselt and Sherwood numbers. The Prandtl number depreciates the skin friction coefficient in the $\mathrm{x}$ and $\mathrm{z}$-directions and the Sherwood number whereas the Nusselt number shows an increasing tendency. The Nusselt number is seen to decrease with increasing radiation parameter while the skin friction coefficient in both the directions and Sherwood number are found to increase. The influence of Schmidt number on the skin friction coefficient in both the directions is to enhance. The Nusselt number reduces while the Sherwood number enhances with increasing Schmidt number. The increasing value of the heat generation parameter enhances the skin friction coefficient in the $\mathrm{x}$ and $\mathrm{z}$ - directions and the Sherwood number while the Nusselt number reduces. The chemical reaction parameter decreases the skin friction coefficient and Nusselt number whereas the Sherwood number enhances. The suction parameter reduces the skin friction coefficient in the $\mathrm{x}$-direction while it increases the skin friction coefficient in the $\mathrm{z}$ - direction. The Nusselt number and Sherwood number are seen to increase with $\mathrm{f}_{\mathrm{w}}$.

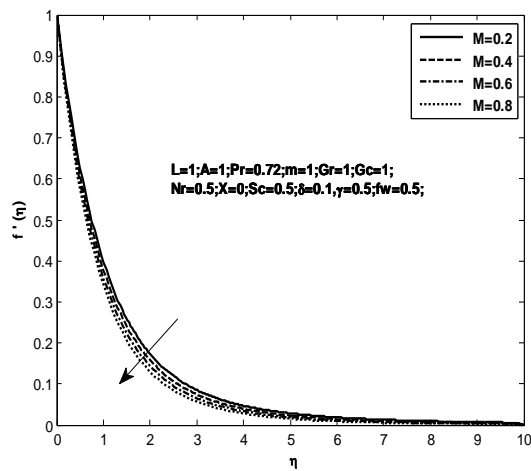

Fig. 1: Primary velocity profiles for different Values of $M$ 


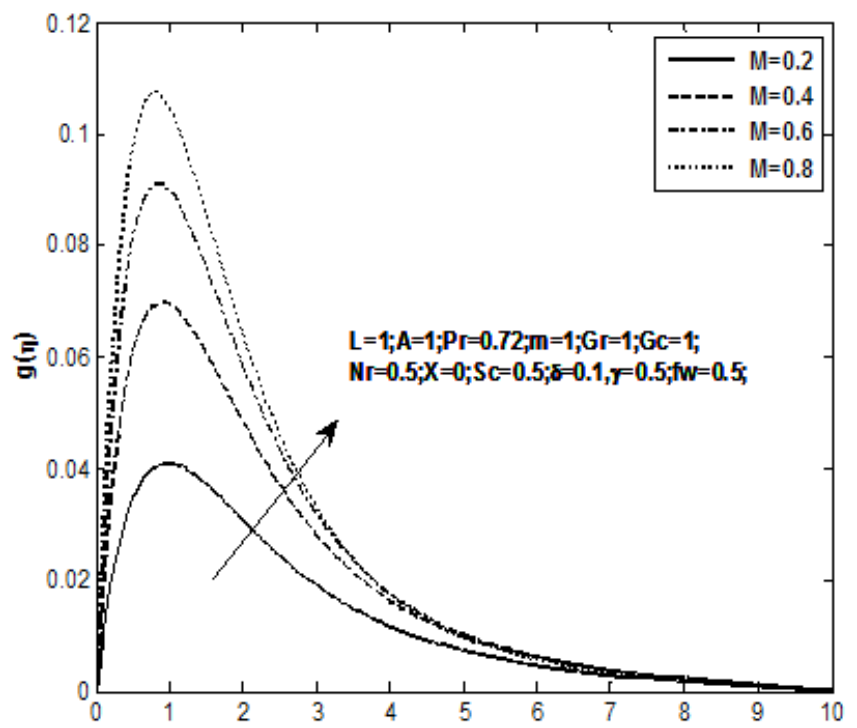

Fig. 2: Secondary velocity profiles for different Values of $M$

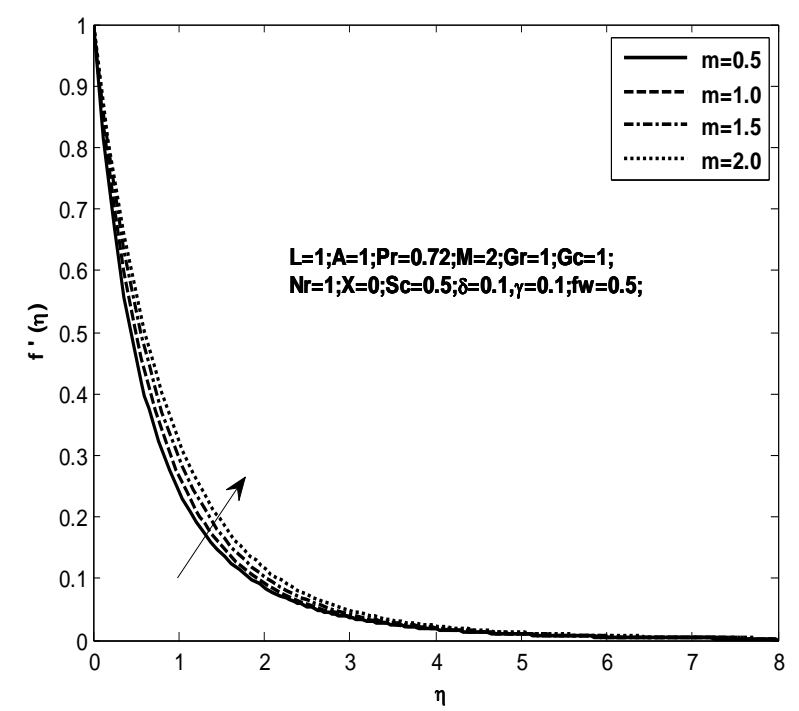

Fig. 3: Primary velocity profiles for different values of $m$

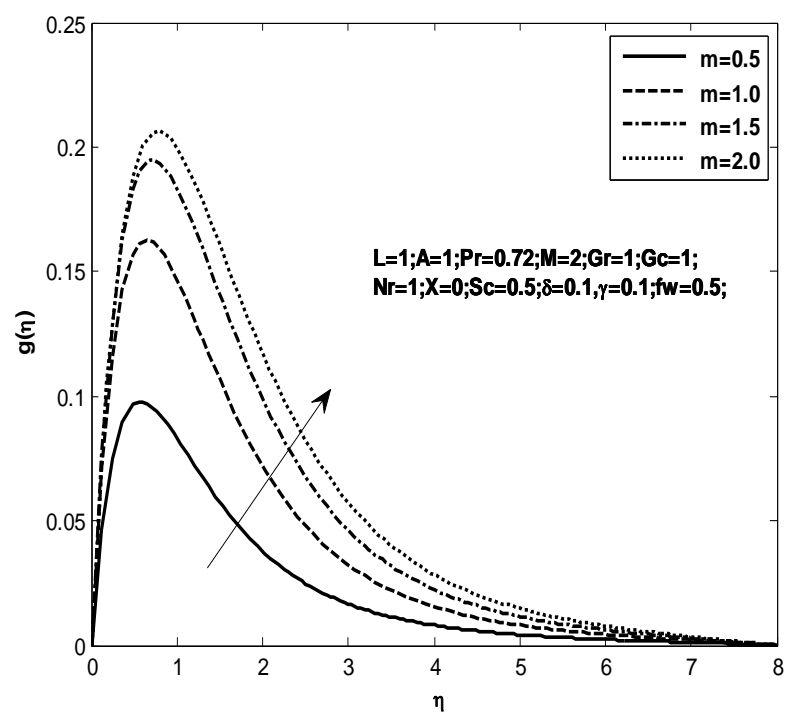

Fig. 4: Secondary velocity profiles for different values of $\mathrm{m}$ 


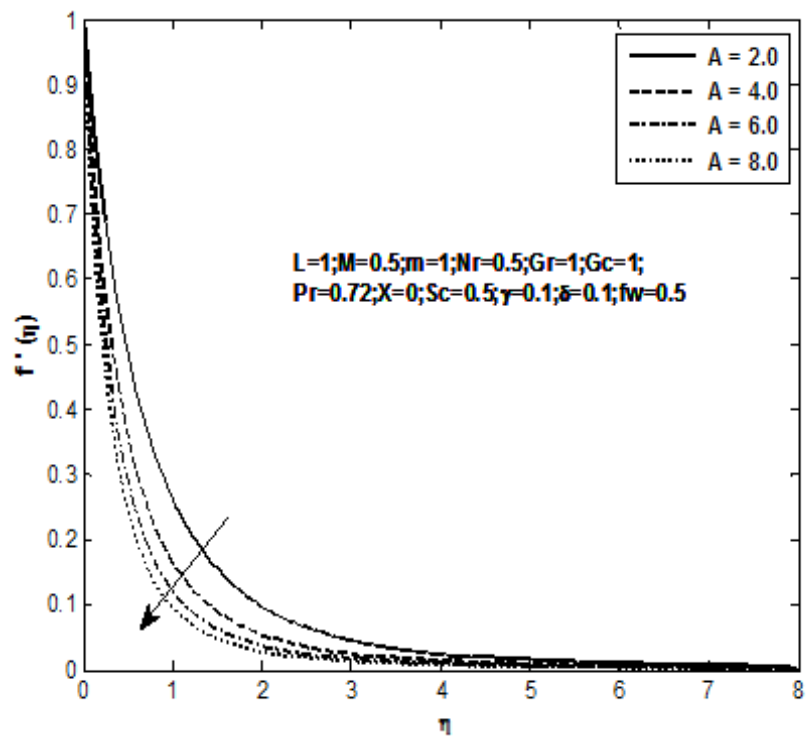

Fig. 5: Primary velocity profiles for different values of A

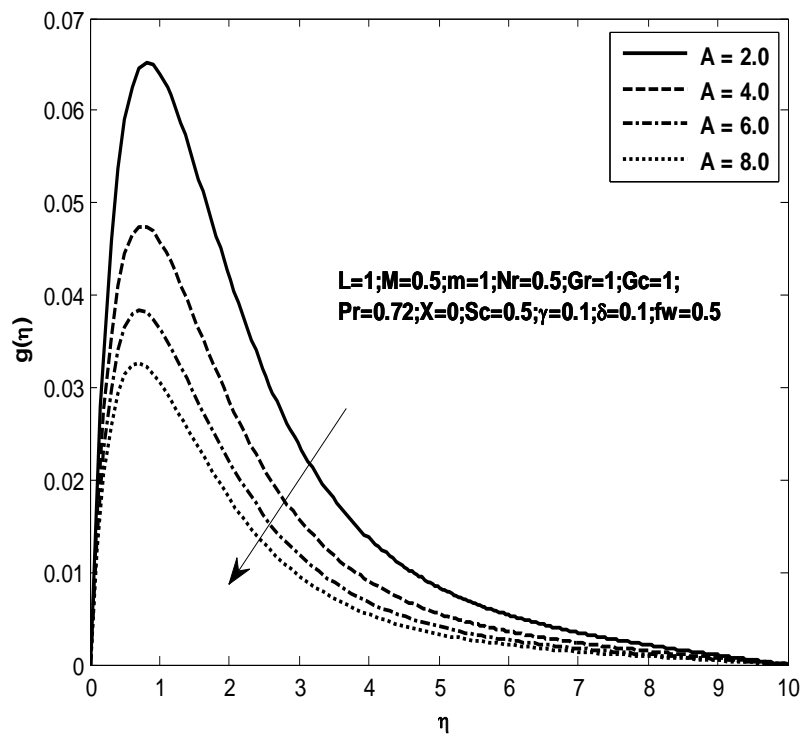

Fig. 6: Secondary velocity profiles for different values of A

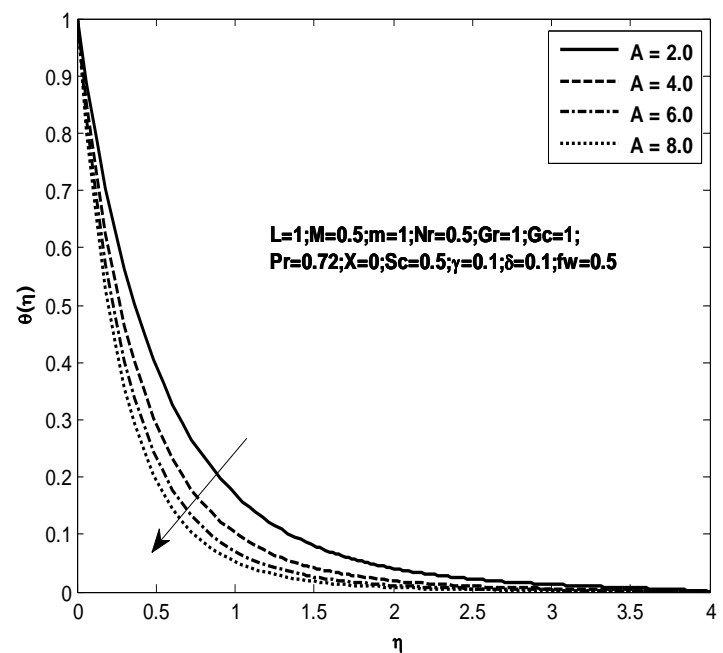

Fig. 7: Temperature profiles for different values of A 


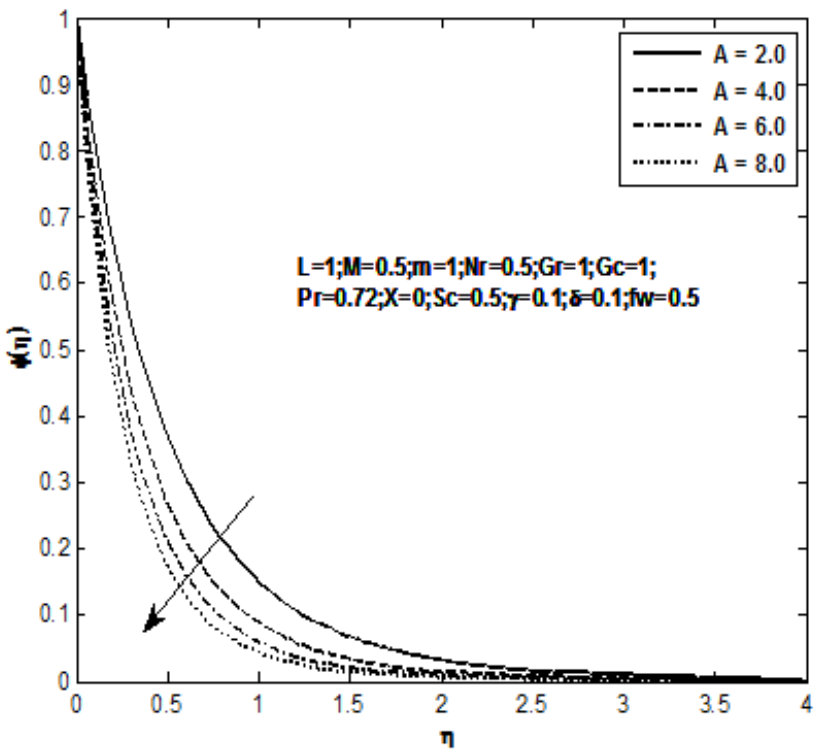

Fig. 8: Concentration profiles for different values of A

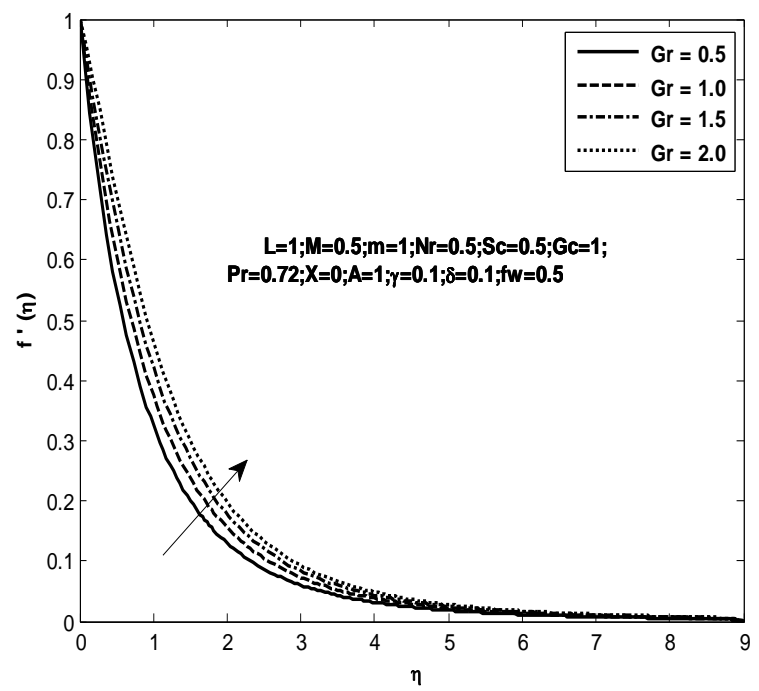

Fig. 9: Primary velocity profiles for different values of Gr

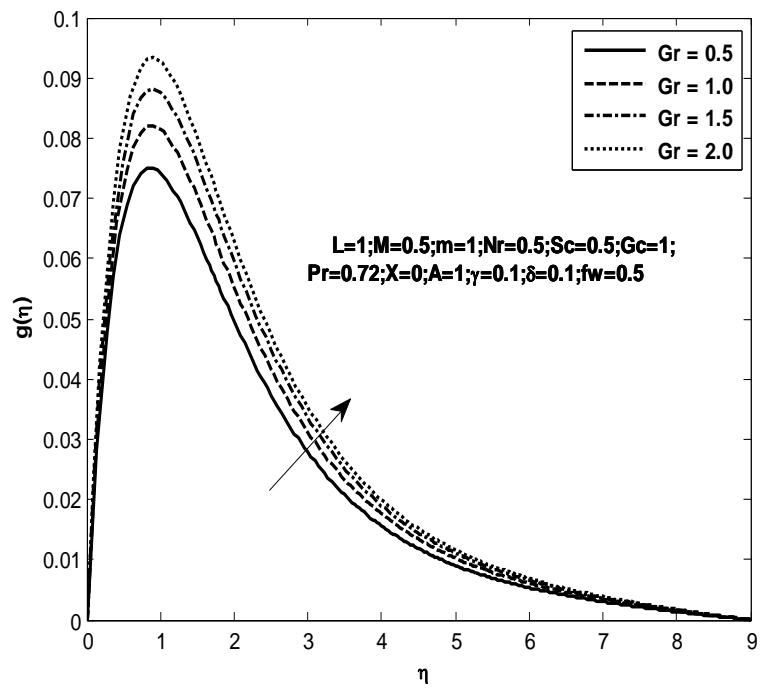

Fig. 10: Secondary velocity profiles for different values of $\mathrm{Gr}$ 


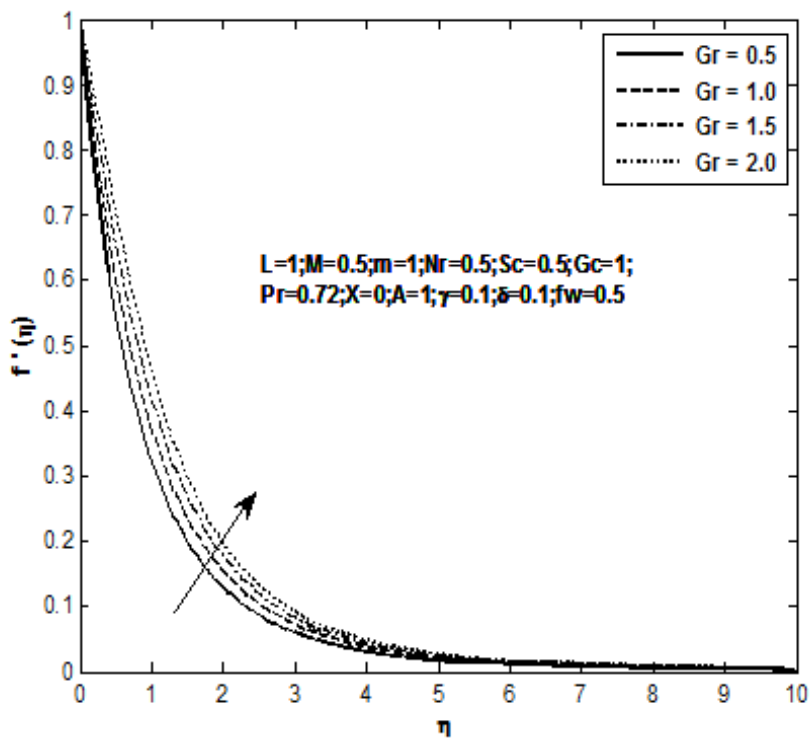

Fig. 11: Primary velocity profiles for different values of $\mathrm{Gc}$

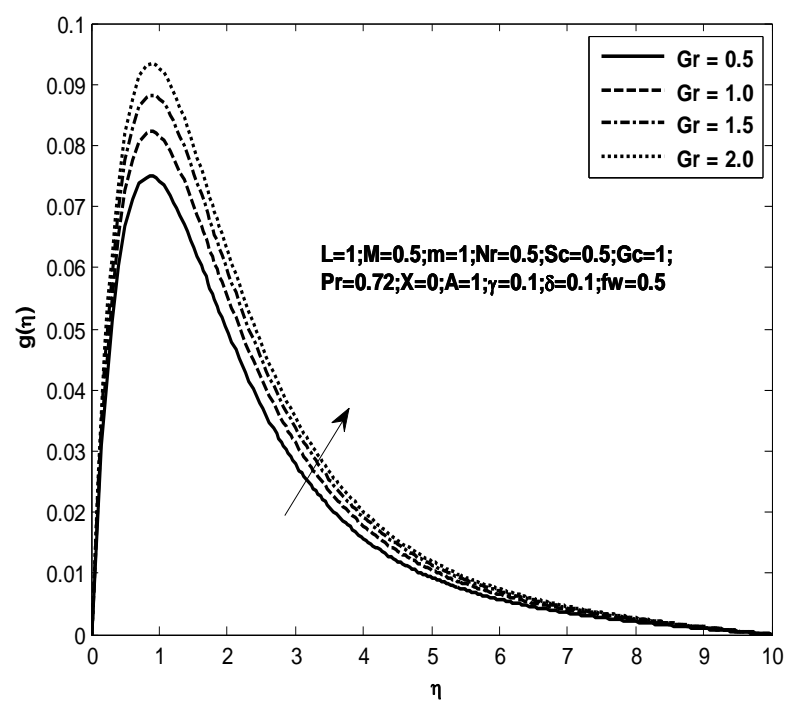

Fig. 12: Secondary velocity profiles for different values of Gc

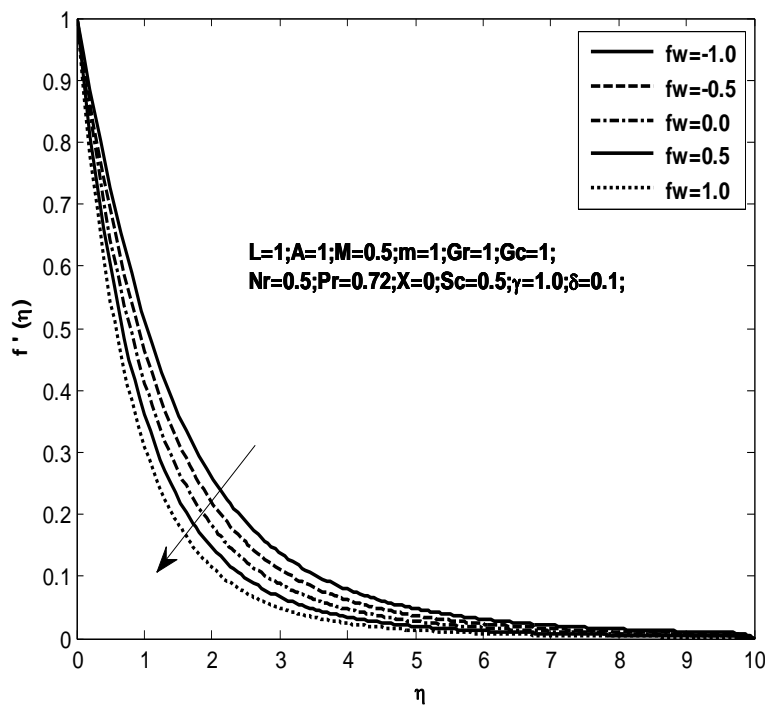

Fig. 13: Primary velocity profiles for different values of $f_{w}$ 


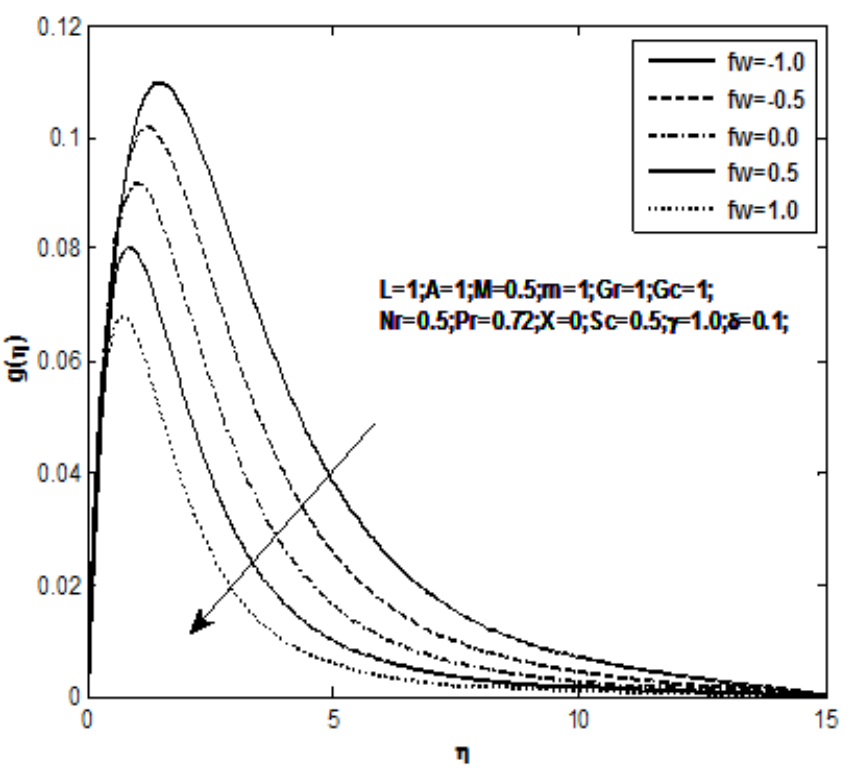

Fig. 14: Secondary velocity profiles for different values of $f_{w}$

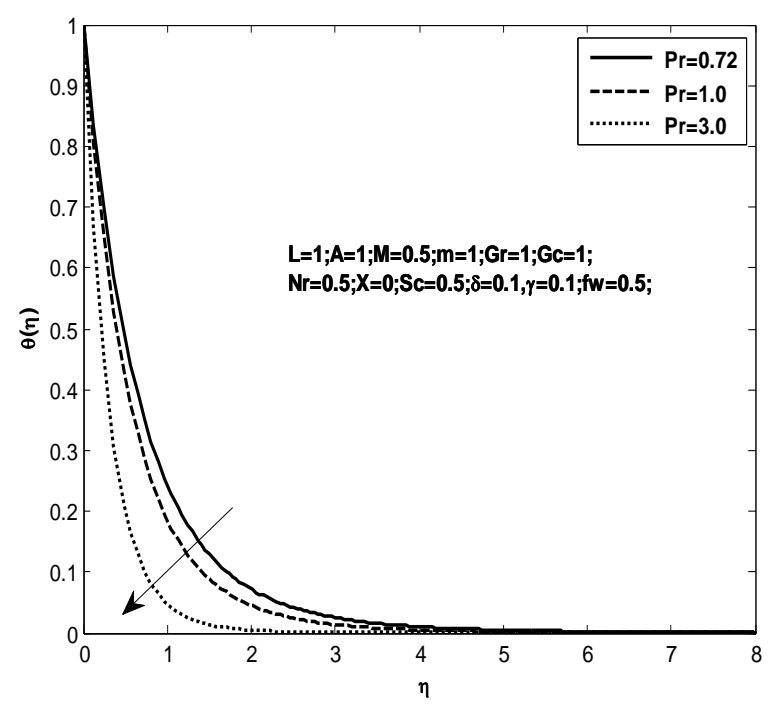

Fig. 15: Temperature profiles for different values of $\operatorname{Pr}$

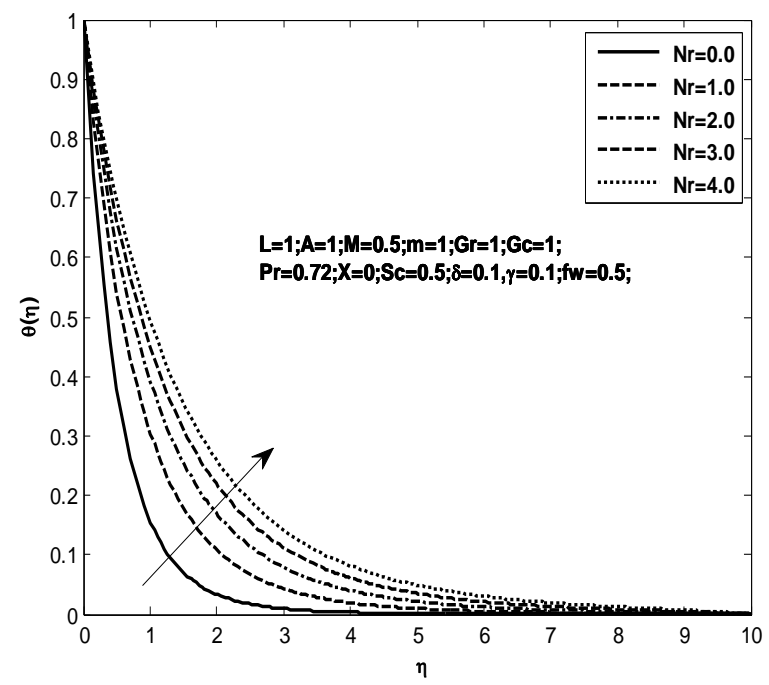

Fig. 16: Temperature profiles for different values of $\mathrm{Nr}$ 


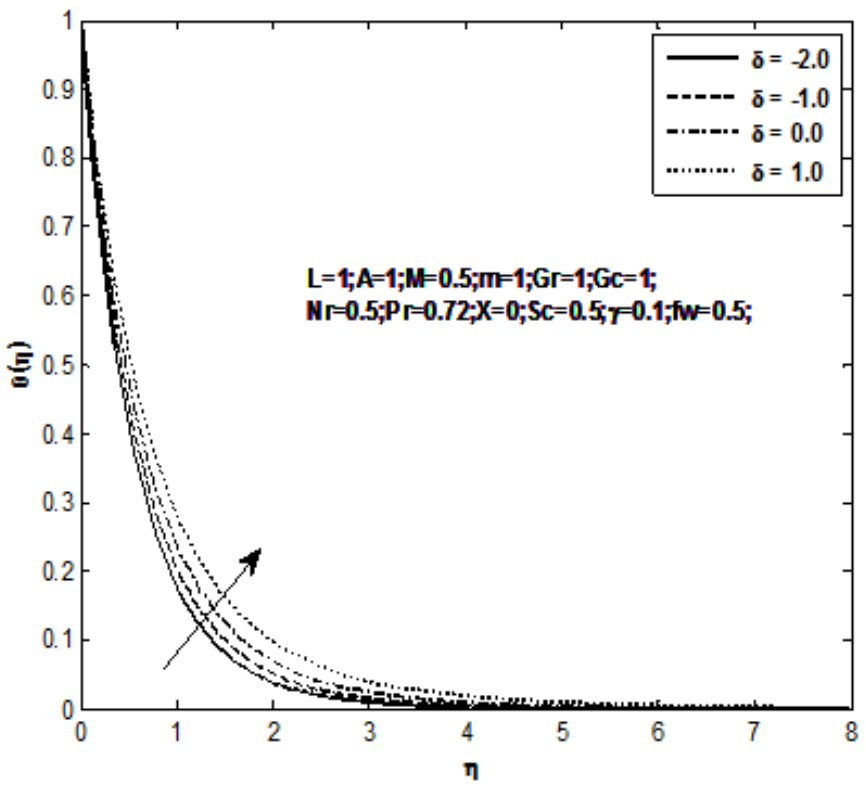

Fig. 17: Temperature profiles for different values of $\delta$

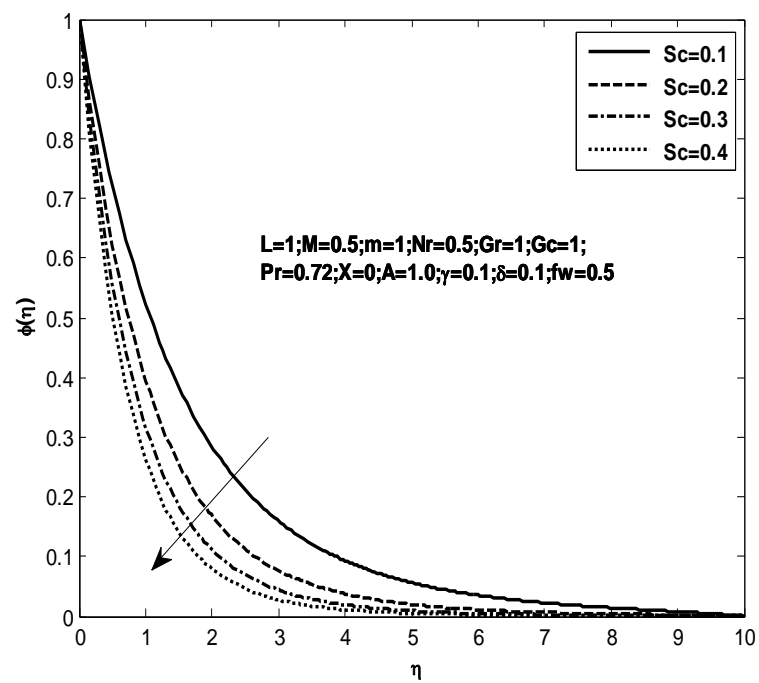

Fig. 18: Concentration profiles for different values of Sc

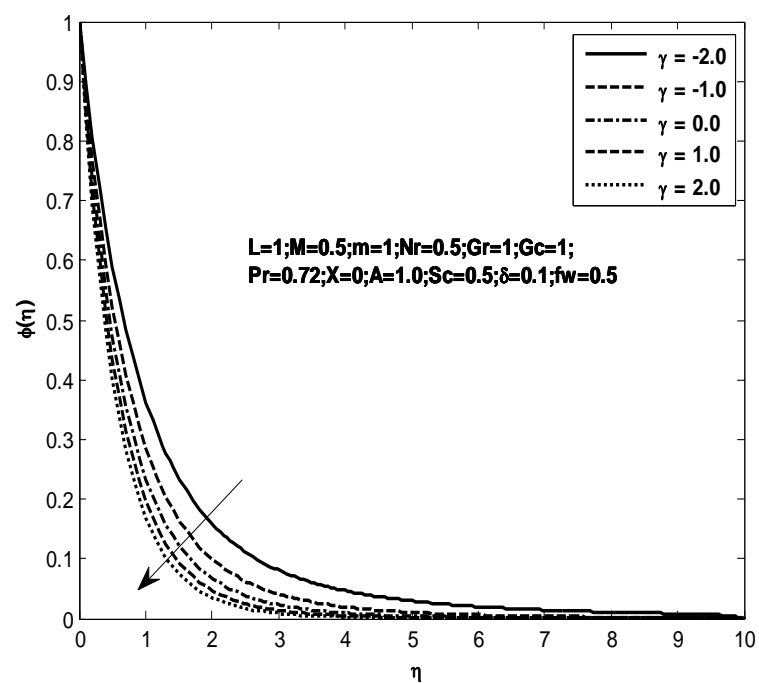

Fig. 19: Concentration profiles for different values of $\gamma$ 
Table 2 Skin friction coefficient, Nusselt number and Sherwood number for various values of pertinent parameters

\begin{tabular}{|c|c|c|c|c|c|c|c|c|c|c|c|c|c|c|c|}
\hline $\mathrm{X}$ & $A$ & M & $\mathrm{m}$ & Gr & $\mathrm{Gc}$ & Pr & $\mathrm{Nr}$ & Sc & $\gamma$ & $\delta$ & $f_{w}$ & $f^{\prime \prime}(0)$ & $h^{\prime}(0)$ & $-\theta^{\prime}(0)$ & $-\phi(0)$ \\
\hline $\begin{array}{l}0.5 \\
1.0 \\
1.5 \\
2.0\end{array}$ & 1.0 & 0.5 & 1.0 & 1.0 & 1.0 & 0.72 & 0.5 & 0.5 & 0.1 & 0.1 & 0.5 & $\begin{array}{l}-1.290661 \\
-1.434928 \\
-1.503910 \\
-1.534652\end{array}$ & $\begin{array}{l}0.250092 \\
0.240728 \\
0.232967 \\
0.226784\end{array}$ & $\begin{array}{l}1.261055 \\
1.078777 \\
0.944628 \\
0.847728\end{array}$ & $\begin{array}{l}1.265480 \\
1.050399 \\
0.889256 \\
0.770849\end{array}$ \\
\hline 0.0 & $\begin{array}{l}2.0 \\
4.0 \\
6.0 \\
8.0 \\
\end{array}$ & 0.5 & 1.0 & 1.0 & 1.0 & 0.72 & 0.5 & 0.5 & 0.1 & 0.1 & 0.5 & $\begin{array}{l}-0.902654 \\
-0.977419 \\
-1.052057 \\
-1.125933 \\
\end{array}$ & $\begin{array}{l}0.118165 \\
0.216380 \\
0.300659 \\
0.374549\end{array}$ & $\begin{array}{l}1.509032 \\
1.506102 \\
1.503177 \\
1.500305 \\
\end{array}$ & $\begin{array}{l}1.614415 \\
1.617071 \\
1.618688 \\
1.619586 \\
\end{array}$ \\
\hline 0.0 & 1.0 & $\begin{array}{l}0.1 \\
0.2 \\
0.3 \\
0.4 \\
\end{array}$ & 1.0 & 1.0 & 1.0 & 0.72 & 0.5 & 0.5 & 0.1 & 0.1 & 0.5 & $\begin{array}{l}-0.865555 \\
-0.902654 \\
-0.939997 \\
-0.977419\end{array}$ & $\begin{array}{l}0.062102 \\
0.118165 \\
0.169312 \\
0.216380\end{array}$ & $\begin{array}{l}1.510470 \\
1.509032 \\
1.507570 \\
1.506102\end{array}$ & $\begin{array}{l}1.612556 \\
1.614415 \\
1.615898 \\
1.617071\end{array}$ \\
\hline 0.0 & 1.0 & 0.5 & $\begin{array}{l}0.5 \\
1.0 \\
1.5 \\
2.0 \\
\end{array}$ & 1.0 & 1.0 & 0.72 & 0.5 & 0.5 & 0.1 & 0.1 & 0.5 & $\begin{array}{l}-1.758923 \\
-1.498655 \\
-1.292045 \\
-1.152010\end{array}$ & $\begin{array}{l}0.483445 \\
0.709265 \\
0.758077 \\
0.764939\end{array}$ & $\begin{array}{l}1.228934 \\
1.234533 \\
1239946 \\
1.244234\end{array}$ & $\begin{array}{l}1540281 \\
1550979 \\
1558007 \\
1561922\end{array}$ \\
\hline 0.0 & 1.0 & 0.5 & 1.0 & $\begin{array}{l}0.5 \\
1.0 \\
1.5 \\
2.0 \\
\end{array}$ & 1.0 & 0.72 & 0.5 & 0.5 & 0.1 & 0.1 & 0.5 & $\begin{array}{l}-1.289134 \\
-1.003911 \\
-0.724291 \\
-0.449705\end{array}$ & $\begin{array}{l}0.245923 \\
0.261625 \\
0.275395 \\
0.287661\end{array}$ & $\begin{array}{l}1.496126 \\
1.505279 \\
1.513990 \\
1.522311\end{array}$ & $\begin{array}{l}1543692 \\
1548921 \\
1553985 \\
1558895\end{array}$ \\
\hline 0.0 & 1.0 & 0.5 & 1.0 & 1.0 & $\begin{array}{l}0.5 \\
1.0 \\
1.5 \\
2.0\end{array}$ & 0.72 & 0.5 & 0.5 & 0.1 & 0.1 & 0.5 & $\begin{array}{l}-1.282761 \\
-1.003919 \\
-0.729632 \\
-0.459532\end{array}$ & $\begin{array}{l}0.247397 \\
0.261675 \\
0.274393 \\
0285858\end{array}$ & $\begin{array}{l}1.490558 \\
1.505279 \\
1.513634 \\
1.521658\end{array}$ & $\begin{array}{l}1543996 \\
1548921 \\
1553716 \\
1558386\end{array}$ \\
\hline 0.0 & 1.0 & 0.5 & 1.0 & 1.0 & 1.0 & $\begin{array}{l}0.72 \\
1.0 \\
2.0\end{array}$ & 0.5 & 0.5 & 0.1 & 0.1 & 0.5 & $\begin{array}{l}-1.003896 \\
-1.047912 \\
-1.201891\end{array}$ & $\begin{array}{l}0.261528 \\
0.255194 \\
0.239418\end{array}$ & $\begin{array}{l}1.505279 \\
1.804369 \\
3.369721\end{array}$ & $\begin{array}{l}1548921 \\
1.547235 \\
1.542651\end{array}$ \\
\hline 0.0 & 1.0 & 0.5 & 1.0 & 1.0 & 1.0 & 0.72 & $\begin{array}{l}0.0 \\
1.0 \\
2.0 \\
3.0 \\
4.0 \\
\end{array}$ & 0.5 & 0.1 & 0.1 & 0.5 & $\begin{array}{l}-1.073048 \\
-0.961039 \\
-0.907802 \\
-0.874537 \\
-0.851062\end{array}$ & $\begin{array}{l}0.252048 \\
0.268724 \\
0.278858 \\
0285948 \\
0.291288\end{array}$ & $\begin{array}{l}1.997173 \\
1.252722 \\
0.981441 \\
0.831351 \\
0.733096\end{array}$ & $\begin{array}{l}1.546353 \\
1.550752 \\
1.553310 \\
1.555078 \\
1.556403\end{array}$ \\
\hline 0.0 & 1.0 & 0.5 & 1.0 & 1.0 & 1.0 & 0.72 & 0.5 & $\begin{array}{l}0.1 \\
0.2 \\
0.3 \\
0.4\end{array}$ & 0.1 & 0.1 & 0.5 & $\begin{array}{l}-0.823359 \\
-0.892641 \\
-0.939362 \\
-0.975006\end{array}$ & $\begin{array}{l}0.295873 \\
0.280688 \\
0.271856 \\
0.265891\end{array}$ & $\begin{array}{l}1.516922 \\
1.512220 \\
1.509203 \\
1.506999\end{array}$ & $\begin{array}{l}0.656839 \\
0.946049 \\
1.174619 \\
1371808\end{array}$ \\
\hline 0.0 & 1.0 & 0.5 & 1.0 & 1.0 & 1.0 & 0.72 & 0.5 & 0.5 & $\begin{array}{l}-2.0 \\
-1.0 \\
0.0 \\
1.0 \\
2.0\end{array}$ & 0.1 & 0.5 & $\begin{array}{l}-1.627937 \\
-1.664574 \\
-1.691613 \\
-1.713085 \\
-1.730894\end{array}$ & $\begin{array}{l}0.096316 \\
0.094265 \\
0.092887 \\
0.091873 \\
0.091084\end{array}$ & $\begin{array}{l}1.487092 \\
1.484712 \\
1.483047 \\
1.481783 \\
1.480774\end{array}$ & $\begin{array}{l}1.080496 \\
1.317461 \\
1.513802 \\
1.685162 \\
1.839186\end{array}$ \\
\hline 0.0 & 1.0 & 0.5 & 1.0 & 1.0 & 1.0 & 0.72 & 0.5 & 0.5 & 0.1 & $\begin{array}{r}-2.0 \\
-1.0 \\
0.0 \\
1.0 \\
\end{array}$ & 0.5 & $\begin{array}{l}-1.050816 \\
-1.030625 \\
-1.006572 \\
-0.976881\end{array}$ & $\begin{array}{l}0.254140 \\
0.257120 \\
0.261061 \\
0.266581\end{array}$ & $\begin{array}{l}1.804382 \\
1.669427 \\
1.521024 \\
1.354007\end{array}$ & $\begin{array}{l}1547037 \\
1.547813 \\
1548805 \\
1550142\end{array}$ \\
\hline 0.0 & 1.0 & 0.5 & 1.0 & 1.0 & 1.0 & 0.72 & 0.5 & 0.5 & 0.1 & 0.1 & $\begin{array}{l}-2.0 \\
-1.0 \\
0.0 \\
1.0 \\
2.0 \\
\end{array}$ & $\begin{array}{l}-0.390868 \\
-0.568626 \\
-0.842626 \\
-1.249399 \\
-1.819070\end{array}$ & $\begin{array}{l}0.165638 \\
0.207461 \\
0.246709 \\
0.260771 \\
0.270972\end{array}$ & $\begin{array}{l}1.059282 \\
1.216351 \\
1.400782 \\
1.614546 \\
1.858798\end{array}$ & $\begin{array}{l}1.160185 \\
1.350197 \\
1.574642 \\
1.834384 \\
2.130134 \\
\end{array}$ \\
\hline
\end{tabular}

\section{Conclusions}

The unsteady boundary layer flow of an incompressible, viscous electrically conducting fluid over an exponentially stretching sheet in the presence of thermal radiation, temperature dependent heat source with chemical reaction and Hall currents is analysed. The following conclusions are drawn:

1. It is observed that the primary velocity decreases with suction, magnetic field parameter, Prandtl number and Schmidt number while an opposite trend is noted with blowing, Hall parameter, thermal radiation and heat source parameter.

2. The secondary velocity experiences an opposite effect to that on primary velocity for variation of magnetic parameter and Hall parameter.

3. The temperature and concentration distributions decrease with increasing magnetic field parameter and increase with Hall parameter.

4. The thickness of the thermal boundary layer increases with increasing values of radiation parameter, blowing and heat generation parameters while a reduction is noticed with suction parameter and heat absorption parameter.

5. The skin friction coefficient corresponding to the primary velocity is reduced with unsteady parameter and increases with Hall parameter. Heat transfer increases with unsteady parameter, thermal radiation parameter and heat generation parameter and decreases with Prandtl number and heat absorption parameter.

6. The mass transfer rate decreases with Schmidt number and chemical reaction parameter while it increases with unsteady parameter.

\section{References}

[1] E. Magyari, and B. Keller, Heat and mass transfer in the boundary layers on an exponentially stretching continuous surface, J. Phys. Appl. Phys., 32, 1999, $577-585$.

[2] E. M. A. Elbashbeshy, Heat transfer over an exponentially stretching continuous surface with suction, Archives of Mechanics, 53(6), $2001,643-651$ 
[3] M. K. Partha, P. V. S. N. Murthy, and G. P. Rajasekhar, Effects of viscous dissipation on the mixed convection heat transfer from an exponentially stretching surface, Heat Mass Transfer, 41, 2005, 360 - 366.

[4] M. Sajid, and T. Hayat, Influence of thermal radiation on the boundary layer flow due to an exponentially stretching sheet, Int. J. Heat Mass Transfer, 35, 2008, 347 - 356.

[5] B. Bidin, and R. Nazar, Numerical solution of the boundary layer flow over an exponentially stretching sheet with thermal radiation, Eur. J. Sci. Res., 33, 2009, $710-717$.

[6] E. Sanjayanand, and S. K. Khan, On heat and mass transfer in a viscoelastic boundary layer flow over an exponentially stretching sheet, International Journal of Thermal Sciences, 45, 2006, 819 - 828.

[7] A. Ishak, MHD boundary layer flow due to an exponentially stretching sheet with radiation effect, Sains Malaysiana, 40(4), 2011, $391-395$.

[8] S. Nadeem, S. Zaheer, and T.Fang, Effects of thermal radiation on the boundary layer flow of a Jeffrey fluid over an exponentially stretching surface, Numer. Algor., 57, 2011, $187-205$

[9] K. Battacharyya, Boundary Layer Flow and Heat Transfer over on Exponentially Shrinking Sheet, CHIN. PHYS. LETT., 28(7), 2011, 074701-1-4.

[10] S. Mukhopadyay, Rama Subba Reddy Gorla, Effects of partial slip on boundary layer flow past a permeable exponential stretching sheet in presence of thermal radiation, Heat Mass Transfer, 48, 2012, 1773 - 1781.

[11] E. M. A. Elbashbeshy, T. G. Emam, and K. M. Abelgaber, Effects of thermal radiation and magnetic field on unsteady mixed convection flow and heat transfer over an exponentially stretching surface with suction in the presence of internal heat generation/absorption, Journal of Egyptian Mathematical Society, 20, 2012, 215 - 222.

[12] S. Mukhopadhyay, M. Golam Arif, and M. Wazed Ali, Effects of partial slip on chemically reactive solute transfer in the boundary layer flow over an exponentially stretching sheet with suction/blowing, Journal of Applied Mechanics and Technical Physics, 54(6), 2013, $928-936$

[13] S. Nadeem, and S. T. Hussain, Heat transfer analysis of Williamson fluid over an exponentially stretching surface, Appl. Math. Mech. - Engl. Ed., 35(4), 2014, 489-502.

[14] M. A. E. Aziz, and T. Nabil, Homotopy analysis solution of hydromagnetic mixed convection flow past an exponentially stretching sheet with Hall current, Mathematical Problems in Engineering, doi: 10.1155/454023, 2012.

[15] E. M. A. Elbashbeshy, Heat transfer over an exponentially stretching continuous surface with suction”, Archives of Mechanics, 53(6), 2001, $643-651$. 